\title{
Introduction to the Special Issue "Bargaining"
}

\author{
Claus-Jochen Haake ${ }^{1} \cdot$ Walter Trockel ${ }^{2}$
}

Published online: 8 December 2020

(c) The Author(s) 2020

\section{JEL Classification C78}

Bargaining between two persons had been a most elementary cell of human interaction. As a theoretical concept it combines the simultaneous presence of (boundedly) rational selfish individuals, respect for the other person, and either person's awareness of both. Chapter 5 of Binmore (1992) titled Making Deals begins:

"Game theory is not only about conflict; it is also about cooperation."

Many books and surveys-we shall list some few at the end of this note-have been devoted to bargaining theory which is a part of game theory with a long history in social science and still a vital in research and applications.

The literature on bargaining offers various approaches to modeling and analyzing bargaining problems. There the interpretation of players as individuals versus representatives of groups or institutions, deviations from equity, distinctions between utility and utility increments, possibilities of effective threats,(in)divisibility of the objects of negotiation and several other aspects may have an impact on the choice of an adequate formal approach to model the scenario under consideration.

Apart from the distinction between non-cooperative strategic and cooperative axiomatic coalitional approaches there are discrete and continuous dynamic models, evolutionary, procedural, probabilistic, decision theoretic, empirical, and experimental approaches to two- or multi-person, one or multiple issue coalitional bargaining with numerous fields of applications. And each of these directions sheds different but new light on the matter. As an attempt to synthesize, the Nash program intends to provide strategic equilibrium supports for axiomatic solutions of coalitional games. Its extension to mechanism theoretic implementation bridges noncooperative behavior and a normative approach.

Claus-Jochen Haake

cjhaake@wiwi.upb.de

Walter Trockel

walter.trockel@uni-bielefeld.de

1 Paderborn University, Paderborn, Germany

2 Bielefeld University, Bielefeld, Germany 
Our selection of potential topics for this special issue had been biased by our own interests and works on bargaining. Nevertheless, all contributors, though having been encouraged by us to contribute, had submitted their articles under the proviso, that publication would be contingent on positive assessments by two independent reviewers. They can, with the benefit of hindsight, be lauded for their excellent constructive reports that added to the quality of this special issue.

We focus in this introduction on short hints to the contents of all articles and underline cross-links between them. From a normative viewpoint there is one common goal that is essential for defining meaningful solution concepts, namely to define a solution that behaves in a consistent way. Hereby, consistency can take several different disguises and is not limited to some particular route one follows to model and solve bargaining problems. All contributions to this special issue, whether via cooperative or non-cooperative approaches, employ direct or indirect notions of consistency as part of the justification of some solution. In an axiomatic approach, one expects a solution to be in- or co-variant under certain transformations of the bargaining problem. Such a transformation may result, e.g., from changes of populations or their utility scales, or from renaming or reordering players. Acceptance of a solution (concept) is ultimately linked to how that reacts to such changes of the environment. Also, rationalizability of a solution may be seen as a consistency property of the solution with a virtual social planner's ordering over possible payoff vectors. In non-cooperative dynamic formulations of the problem, consistency over time plays a crucial part in stabilizing agreements. Finally, following the Nash program, we may say that the rules of the game have to be chosen consistently across populations, so that equilibrium actions trigger the cooperative solution. In sum, notions of consistency remove arbitrariness from the solution concept and therefore help to reveal the fairness idea and desirable properties behind it that go beyond the widely accepted concept of Pareto efficiency.

Within this special issue, there is a slight focus on cooperative modeling and the axiomatic approach, indicating that this is still an important and active branch of bargaining. Since Nash's (1950, 1953) pioneering works, theorists have more and more extended the original framework and scrutinized the results, methods and procedures in a variety of applications, while maintaining the principles of justifying a solution. For instance, leaving the original setup, non-convex bargaining has become an interesting section of cooperative bargaining. A very detailed treatment of this literature, supplemented by their own recent works, is the contribution by $\mathrm{Xu}$ and Yoshihara. One interesting consequence of the non-convex framework is that there anonymity and symmetry axioms are effectively falling apart. Their discussion of consistency properties builds a link to Thomson's contribution, where he modifies Lensberg's (1988) axiomatization of the Nash solution in a convex multipopulations framework by removing some conceptual friction between consistency and continuity. He does this by replacing the employed convergence of bargaining problems with respect to the Hausdorff distance by stronger requirements, leading to a weaker continuity assumption. While Thomson explores consistency in the sense that the solution is supposed to behave consistently, when the population is reduced, the contribution by Chun uses the opposite direction, known as converse consistency. This axiom requires that the solutions of problems with fewer players 
generate the solution when the population grows. However, his results show that this version of consistency is incompatible with Pareto efficiency and either of the axioms ${ }^{1}$ that are crucial in the characterization of the two most prominent bargaining solutions by Nash (1950) and Kalai and Smorodinsky (1975). A particular consequence is that the context, in which one argues for or against a particular bargaining solution, does matter. Even a solution that fulfills many desirable properties except (converse) consistency may fail to be a good candidate to resolve bargaining problems, when variations of the population become an integral issue.

The consistency concepts above are independent of the size of the (population) change in the bargaining environment and therefore might be too demanding to be fully satisfied. As a result, local versions of consistency help to partially overcome this problem. The contribution by Borm, Funaki, and Ju studies a model with a wellspecified active coalition of players. Entry to or exit from this coalition causes external effects, i.e. it changes the payoff of all players. Therefore, entry or exit may be used as threats or arguments to receive a compensation for non-execution. Hence, one can define a bargaining problem. The authors introduce a corresponding solution, termed the balanced threat agreement, and characterize it by means of a local consistency axiom. In this context, locality makes sense as the underlying model rests on changes from unilateral deviations. Nonetheless, the axiom is still closely related to the one Thomson uses in his contribution.

The discussion of rationalizability ${ }^{2}$ of bargaining solutions in the $\mathrm{Xu}$ and Yoshihara article connects to the contribution by Gerber. Her article provides a correct version of Roth's (1978) representation of the Nash solution as a von NeumannMorgenstern utility function.

Despite the bias of this issue towards cooperative bargaining non-cooperative bargaining is in the background when the Nash program or even mechanism theoretic implementation of axiomatic bargaining solutions are under focus. This is for instance the case with the relatively small literature concerned with Meta Bargaining. Game theoretic solutions are employed here as players' potential strategies in a non-cooperative strategic game. Initiated by van Damme (1986) and based on an axiomatic restriction of feasible solutions it had led to the first weak implementation in Nash equilibrium of the Nash bargaining solution. In a similar way, yet with different axiomatic restrictions, the Kalai-Smorodinsky solution had been weakly implemented by Naeve-Steinweg $(2002)^{3}$

Marco, Peris and Subiza contribute to this issue an axiomatically determined procedure for Meta-Bargaining that determines the Nash solution. They discuss the relation to the literature on Meta Bargaining and other axiomatically founded procedures as contrasted with the resulting solutions. In a dynamic framework, Flamini's contribution

\footnotetext{
1 Independence of Irrelevant Alternatives and Individual Monotonicity.

2 cf. Trockel (1999, 2008).

3 A weak meta-bargaining implementation of the Nash solution without any feasibility restriction on the solutions usable as strategies is due to Trockel (2002). For a (strong, non Meta-Bargaining) implementation of the Nash solution in Nash equilibrium see Trockel (2000); cf. Haake and Trockel (2010). Different implementations of the Kalai-Smorodinsky solution had been provided by Moulin (1984) and Haake (2009).
} 
studies a non-cooperative dynamic (bargaining) game, in which two players are allowed to invest part of the stock in the next period. The players bargain according to a continuous alternating offer protocol with delays, in which proposals consist of how much players demand for themselves and how much they want to save for the future. Under fairly restrictive conditions, e.g., when players are symmetric and there are no delays, this game form implements an efficient outcome. Thanks to the Markovian property, i.e., decisions only depend on the current state, the solution (Markov perfect equilibrium) is dynamically consistent. Hence, Flamini's contribution can be viewed as a positive approach to (dynamic) bargaining, so that consistency is not imposed on the solution concept, but result from its application.

To conclude, the contributions in this special issue demonstrate that bargaining theory is a vital field of research and offers various different approaches to appropriately describe the problem, its specialties and its solution alternatives. Nonetheless, the axiomatic method guarantees that there is a common basis that allows a comparison of different strands of models. As this issue contains only a small collection of current research in bargaining, we finalize our introduction with a list of selected earlier books, book chapters and surveys that summarize what has been done and what still needs to be done in the future.

Funding Open Access funding enabled and organized by Projekt DEAL.

Open Access This article is licensed under a Creative Commons Attribution 4.0 International License, which permits use, sharing, adaptation, distribution and reproduction in any medium or format, as long as you give appropriate credit to the original author(s) and the source, provide a link to the Creative Commons licence, and indicate if changes were made. The images or other third party material in this article are included in the article's Creative Commons licence, unless indicated otherwise in a credit line to the material. If material is not included in the article's Creative Commons licence and your intended use is not permitted by statutory regulation or exceeds the permitted use, you will need to obtain permission directly from the copyright holder. To view a copy of this licence, visit http://creativecommons.org/licen ses/by/4.0/.

\section{References}

Binmore, K. (1992). Fun and games: a text on game theory. Lexington: DC Heath.

Haake, C. J. (2009). Two support results for the Kalai-Smorodinsky solution in small object division markets. Mathematical Social Sciences, 57(2), 177-187.

Haake, C. J., \& Trockel, W. (2010). On Maskin monotonicity of solution based social choice rules. Review of Economic Design, 14(1-2), 17-25.

Kalai, E., \& Smorodinsky, M. (1975). Other solutions to Nash's bargaining problem. Econometrica: Journal of the Econometric Society, 43(3), 513-518.

Lensberg, T. (1988). Stability and the Nash solution. Journal of Economic Theory, 45(2), 330-341.

Moulin, H. (1984). Implementing the Kalai-Smorodinsky bargaining solution. Journal of Economic Theory, $33(1), 32-45$.

Naeve-Steinweg, E. (2002). Mechanisms supporting the Kalai-Smorodinsky solution. Mathematical Social Sciences, 44(1), 25-36.

Nash, J. F. (1950). The bargaining problem. Econometrica: Journal of the Econometric Society, 18(2), $155-162$.

Nash, J. (1953). Two-person cooperative games. Econometrica: Journal of the Econometric Society, 21(1), 128-140. 
Roth, A. E. (1978). The Nash solution and the utility of bargaining. Econometrica: Journal of the Econometric Society, 46(3), 587-594.

Trockel, W. (1999). Rationalizability of the Nash bargaining solution. Journal of Economics - Zeitschrift für Nationalökonomie (Supplement 8 pp 159-165). International Conference on Mathematical Utility Theory, Essen, Germany, 1997.

Trockel, W. (2000). Implementations of the Nash solution based on its Walrasian characterization. Economic Theory, 16(2), 277-294.

Trockel, W. (2002). A universal meta bargaining implementation of the Nash solution. Social Choice and Welfare, 19(3), 581-586.

Trockel, W. (2008). The Nash product is a utility representation of the Pareto ordering. Economics Letters, 99(2), 220-222.

van Damme, E. (1986). The Nash bargaining solution is optimal. Journal of Economic Theory, 38(1), 78-100.

\section{Books, Chapters in Books, Survey Articles}

Binmore, K., \& Dasgupta, P. (Eds) (1987). Economics of bargaining. Oxford: Basil Blackwell.

Gale, D. (2000). Strategic foundations of general equilibrium: dynamic matching and bargaining games. Cambridge: Cambridge University Press.

Hargreaves-Heap, S., \& Varoufakis, Y. (1995). Bargaining games. In Game theory: a critical introduction, chap 4, (pp. 111-145). London: Routledge,

Klemisch-Ahlert, M. (1996). Bargaining in economic and ethical environments: an experimental study and normative solution concepts (Vol. 436). Lecture Notes in Economics and Mathematical Systems. Berlin: Springer.

Luce, R. D., \& Raiffa, H. (1957). Two-person cooperative games. In Games and decisions, chap 6. Hoboken: Wiley.

Maschler, M., Solan, E., \& Zamir, S. (2013). Bargaining games. In Game theory, chap 15, (pp. 622658). Cambridge: Cambridge University Press.

Morgenstern, O. (1973). Ingolf ståhl: Bargaining theory. The Swedish Journal of Economics, 75(4), 410-413.

Myerson, R. B. (1991). Bargaining and cooperation. Game theory, chap 8, (pp. 370-416). Cambridge: Harvard University Press.

Napel, S. (2012). Bilateral bargaining: theory and applications (Vol. 518). Heidelberg: Springer.

Osbourne, M., \& Rubinstein, A. (1990). Bargaining and markets. San Diego: Academic Press.

Peters, H. (2008). Bargaining. Game theory: a multi-leveled approach, chap 21, (pp. 375-386). Berlin: Springer,

Peters, H. J. (1992). Axiomatic bargaining game theory. Berlin: Springer.

Roemer, J. E. (1998). Axiomatic bargaining theory. In Theories of dstributive justice, chap 2, (pp. 51-93). Cambridge:Harvard University Press.

Rosenmüller, J. (2000). Bargaining. In Game theory: stochastics, Information, strategies and cooperation, theory and decision library $C$, chap 8, (Vol. 25). Berlin: Springer.

Roth, A. E. (Ed.). (1985). Game-theoretic models of bargaining. Cambridge: Cambridge University Press.

Roth, A. E. (2012). Axiomatic models of bargining (Vol. 170). Berlin: Springer.

Serrano, R. (2005). Fifty years of the Nash program, 1953-2003. Investigaciones Económicas, 29(2), 219-258.

Serrano, R. (2008a). Bargaining. In S. N. Durlauf, L. E. Blume (Ed.), The new palgrave dictionary of economics (pp. 1-19). London: Palgrave Macmillan.

Serrano, R. (2008b). Nash program. In S. N. Durlauf, L. E. Blume (Ed.), The new palgrave dictionary of economics (pp. 256-262). London: Palgrave Macmillan.

Serrano, R. (2020). Sixty-seven years of the Nash program: Time for retirement?. SERIEs. https://doi. org/10.1007/s13209-020-00221-5

Ståhl, I. (1972). Bargaining theory. Stockholm: The Economic Research Institute at the Stockholm School of Eonomics.

Sutton, J. (1986). Non-cooperative bargaining theory: An introduction. The Review of Economic Studies, 53(5), 709-724. 
Thomson, W. (1994). Cooperative models of bargaining. In R. Aumann \& S. Hart (Eds.), Handbook of game theory with economic applications (Vol. 2, pp. 1237-1284). North Holland.

Thomson, W., \& Lensberg, T. (2006). Axiomatic theory of bargaining with a variable number of agents. Cambridge: Cambridge University Press.

Young, H. P. (1998). Bargaining. In Individual strategy and social structure: an evolutionary theory of institutions, chap 2, (pp. 113-130). Princeton: Princeton University Press.

Publisher's Note Springer Nature remains neutral with regard to jurisdictional claims in published maps and institutional affiliations. 